\title{
Is minimally invasive thoracoscopic surgery the new benchmark for treating mitral valve disease?
}

\author{
Andrew B. Goldstone, Y. Joseph Woo \\ Department of Cardiothoracic Surgery, Stanford University School of Medicine, Stanford, CA, USA \\ Correspondence to: Y. Joseph Woo, MD. Norman E. Shumway Professor and Chair, Department of Cardiothoracic Surgery, Professor, by \\ courtesy, Department of Bioengineering, Stanford University, Falk Building CV-235, 300 Pasteur Drive, Stanford, CA 94305-5407, USA. \\ Email: joswoo@stanford.edu.
}

\begin{abstract}
The treatment of mitral valve disease remains dynamic; surgeons and patients must now choose between many different surgical options when addressing mitral regurgitation and mitral stenosis. Notably, advances in imaging and surgical instrumentation allow surgeons to perform less invasive mitral valve surgery that spares the sternum. With favorable long-term data now emerging, we compare the benefits and risks of thoracoscopic mitral valve surgery with that through conventional sternotomy or surgery that is robotassisted.
\end{abstract}

Keywords: Mitral valve repair; mitral valve surgery; minimally invasive

Submitted Feb 02, 2016. Accepted for publication Mar 17, 2016.

doi: 10.21037/acs.2016.03.18

View this article at: http://dx.doi.org/10.21037/acs.2016.03.18

The increasing popularity of less invasive procedures has affected nearly every surgical specialty, including cardiac surgery. Patients requiring surgery frequently seek minimally invasive operations that promise smaller-incisions and, ideally, better tolerated-incisions. Consequently, valve disease specialists have been charged with reforming valve interventions to minimize the burden of surgery without compromising overall cardiovascular care. Advancements in imaging, surgical instrumentation, and robotic technology have enabled surgeons to perform complex cardiac surgical procedures through small incisions, often eliminating the need for sternotomy or cardiopulmonary bypass (Figure 1) (1-3). Enter the lower hemisternotomy, thoracoscopyassisted right minithoracotomy, and robot-assisted port access approaches to mitral valve surgery. Each approach carries distinct advantages and disadvantages when compared to conventional sternotomy, as well as when compared to one another. In the current era, we believe that thoracoscopic mitral valve surgery has supplanted median sternotomy as the optimal surgical approach. This opinion is based on reproducible clinical efficacy, minimal incremental resource utilization, and capacity for widespread adoption.

\section{Comparison to sternotomy approach}

Requisite to implementing a minimally invasive approach is the performance of the new procedure to be equal or superior to that of the reference standard approach. Therefore, thoracoscopic mitral valve surgery must be as safe, effective, and durable as the traditional "open" approach. To date, no comparison study has shown a significant difference in operative mortality when comparing minimally invasive mitral valve surgery to that through median sternotomy (4-10). Initial experiences with thoracoscopic mitral valve surgery documented mortality rates near $10 \%$ (11). However, more recent studies, including our own, reproducibly demonstrate mortality rates less than $1 \%$, particularly in the case of degenerative mitral valve disease $(4,5,7,12)$. Furthermore, a recent metaanalysis that pooled over 20,000 patients reported no difference in operative mortality between video-assisted and conventional sternotomy approaches (13). Intermediate and long-term survival is equally encouraging. Propensity score matched comparisons of minimally invasive and sternotomy approaches to mitral valve surgery reveal similar survival up to a decade after surgery (5-7). In our 

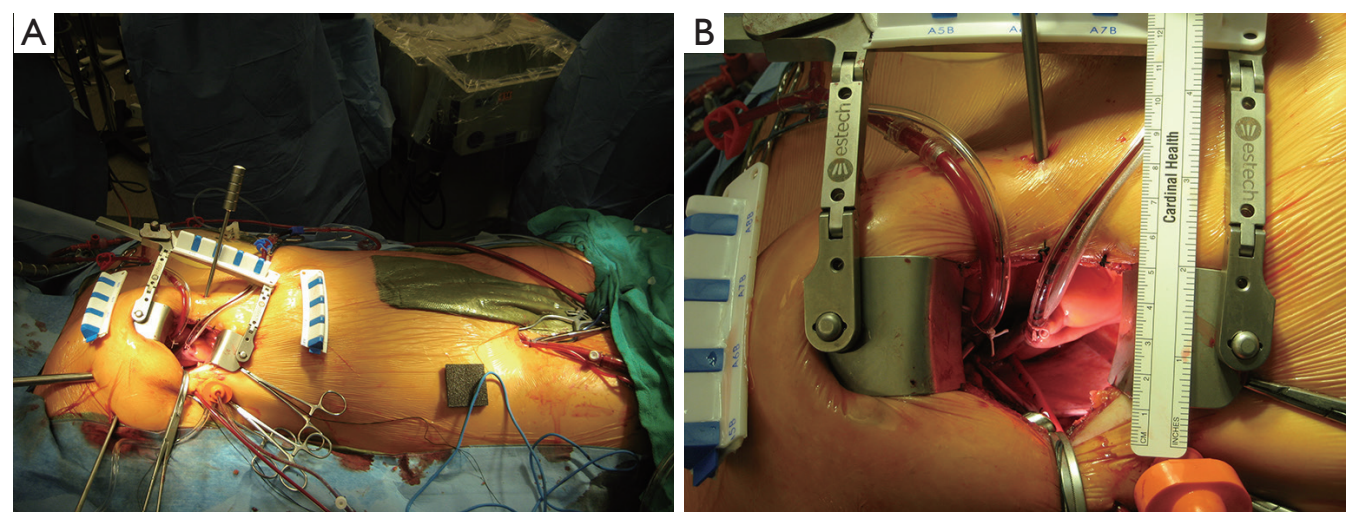

Figure 1 Standard setup for thoracoscopic mitral valve surgery. (A) Thoracoscopic approach via a right minithoracotomy with femoral vessel cannulation; (B) the surgery is performed through a two-inch utility incision.

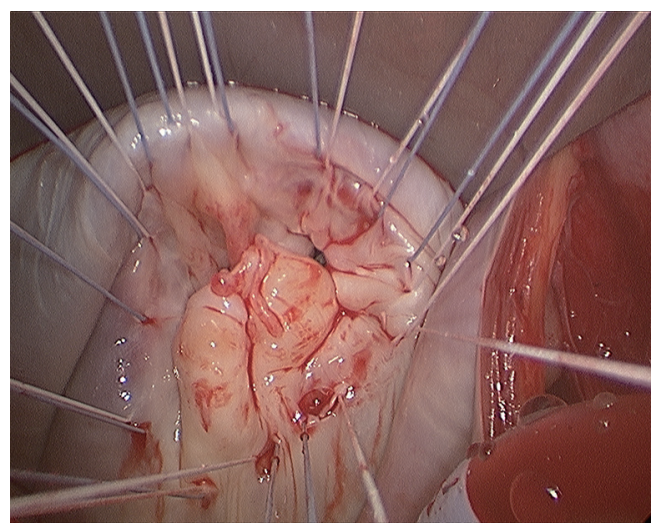

Figure 2 The right minithoracotomy facilitates excellent visualization of the diseased mitral valve.

analysis of 402 well-matched patient pairs with mitral regurgitation of any etiology, 9-year survival was $96 \%$ after thoracoscopic mitral valve repair, and $89 \%$ following the conventional approach (7).

Advocates against thoracoscopic mitral valve surgery argue that the increased distance from the mitral valve may limit the repair techniques available to the surgeon, thereby hindering repair rates and repair durability. However, the approach through the right anterolateral thoracotomy actually provides a more en face view of the mitral valve, and a more medial incision yields a very manageable distance such that all sutures may be tied by hand (Figure 2). Examination of the literature demonstrates that operative approach does not appear to significantly impact the likelihood of successful mitral valve repair $(7,14)$ or durability (15). In a propensity score matched comparison of patients with degenerative mitral regurgitation, moderate mitral regurgitation only developed in 16 patients (4\%) and recurrence did not differ by surgical approach (15). Thoracoscopic mitral valve repair is also effective in treating Barlow's disease. In a series of 145 patients, Borger and colleagues successfully repaired $95 \%$ through a right minithoracotomy, and 10-year freedom from reoperation was $94 \% \pm 3 \%(16)$.

In addition to benefits of improved cosmesis, thoracoscopic mitral valve surgery was pioneered with the intent of reducing morbidity, postoperative pain, blood loss, hospital length of stay, and time to return to normal activity. Reductions in postoperative bleeding and transfusion requirements after minimally invasive mitral valve surgery are likely due to smaller incisions and less extensive mediastinal dissection $(5,7,8,17-23)$. Other centers, including our own, have also demonstrated significant associations between less invasive mitral valve surgery and reduced bleeding and transfusion (7). Two separate metaanalyses reported significant reductions in postoperative bleeding and/or transfusion requirements when surgery was performed via right minithoracotomy $(10,13)$. Decreased rates of blood transfusion and avoidance of surgery in the xiphisternal region are also implicated in the lower rates of deep wound infection associated with thoracoscopic mitral valve surgery (24).

Thoracoscopic mitral valve surgery may also permit earlier recovery of pulmonary function. A number of studies, including meta-analyses, documented reductions in the duration of mechanical ventilation when minimally invasive approaches were utilized $(8,10,12,13,19,20,25,26)$. Yet other experienced centers have not shown such a 
benefit, including our own $(7,8)$. Expedited extubation may result from enhanced preservation of mechanical chest wall functionality, or alternatively from different management protocols.

Less invasive mitral valve surgery reproducibly shortens ICU and hospital length of stay compared to that through median sternotomy $(6,19,20,22,27,28)$. This benefit may be more pronounced in sternal-sparing mitral valve surgery. More than half of the studies identified in a meta-analysis by Modi and colleagues reported significant reductions in the length of hospital stay (9). Although the overall meta-analysis failed to demonstrate a significant reduction in length of hospital stay, more recent meta-analyses $(10,13)$ that focused only on sternal-sparing surgery documented significantly shorter ICU [weighted mean difference (WMD), -19.4 hour; 95\% CI, -27.1 to -11.6 hours] and hospital stays (WMD, -2.0 days; 95\% CI, -2.4 to -1.5 days) (13). This benefit has also been observed in higher risk patient populations, including the elderly (29) and obese (30).

Postoperative pain and scar cosmesis would presumably be improved by smaller incisions but little evidence exists that examines these endpoints. In a survey of 187 patients who underwent thoracoscopy-assisted mitral valve repair, $93 \%$ of patients were highly satisfied with the procedure and reported mild or no postoperative pain, and $99 \%$ of patients believed their scar was aesthetically pleasing (31). When 22 patients who underwent reoperative mitral valve surgery via minithoracotomy after previous median sternotomy were interviewed, they all felt their recovery was more rapid and less painful than after their original sternotomy (32). Finally, one experienced center documented that patients return to normal activity five weeks earlier after thoracoscopy-assisted mitral valve surgery than after a median sternotomy (26).

Procedural cost and resource utilization are increasingly important factors in evaluating different treatments. Multiple groups demonstrated that shorter hospital stays after less invasive mitral valve surgery translate to cost saving ranging from $7 \%$ to $34 \%$ $(18,19,33)$. Further economic benefit may stem from lower rehabilitation requirements and lower rates of early rehospitaliztion $(7,18)$. In an in-depth economic analysis of cost differences between minimally invasive and sternotomy approaches to mitral valve surgery, Iribarne and colleagues concluded that minimally invasive mitral valve surgery was both cost effective and cost saving: minimally invasive operations were associated with average savings of greater than $\$ 9,000$ per patient (34). This cost-savings benefit was confirmed in a multi-institutional database (35) and meta-analysis (13).

\section{Comparison to robot-assisted approach}

It is important to note that robot-assisted port access mitral valve surgery has become increasingly adopted at certain reference centers. Initial experience with robotic technology has been quite favorable (22,36-39). Experienced robotic surgeons have demonstrated that the standard surgical mitral repair techniques are replicated with robot assistance and allow for safe and effective repair of all types of leaflet prolapse $(36,39,40)$. In addition to the benefit of reduced ICU and hospital stays, postoperative survival and durability of mitral valve repair have consistently and reproducibly been comparable to that of the reference standard approach, median sternotomy $(36,38,40,41)$. However, little to no evidence objectively compares robot-assisted mitral valve surgery to thoracoscopic surgery. Rather, most analyses combine thoracoscopy and robot-assisted mitral valve surgery into the same group.

We prefer thoracoscopic mitral valve surgery over that of totally endoscopic, robot-assisted mitral valve surgery because tactile feedback is maintained, a knot pushing device is unnecessary, central aortic cannulation is possible, cross-clamp and cardiopulmonary bypass times are shorter, and we believe the procedure is more conducive to teaching trainees. The learning curve associated with both thoracoscopic and robotic mitral valve surgery is clear, but the two have not been directly compared. Holzhey and colleagues analyzed 3,895 mitral valve surgeries performed via right minithoracotomy by 17 surgeons (42). Using cumulative sum sequential probability analysis, they concluded that the typical number of operations to overcome the minimally invasive learning curve was between 75 and 125 . Alternatively, Chitwood and colleagues demonstrated that rates of repair failure fell from $7 \%$ to $4.5 \%$ after the first 100 robotic mitral valve procedures (43), but it is unclear if further experience with robotic surgery is required to obtain optimal results.

\section{Limitations of thoracoscopic mitral valve surgery}

Risks of thoracoscopic mitral valve surgery depend on the cannulation strategy employed. The increased utilization of peripheral cannulation and endoaortic balloon occlusion have seemingly translated to an increased perioperative 
risk of stroke (RR, $1.79 ; 95 \%$ CI, 1.35 to 2.38 ), aortic dissection/injury (RR, 5.68; 95\% CI, 1.23 to 26.17 ), and groin infection (RR, 5.62; 95\% CI, 1.26 to 25.13 ) (10). However, a recent meta-analysis demonstrated that the risk of stroke did not differ between right minithoracotomy and sternotomy approaches (13). We opt for central aortic cannulation in patients with significant peripheral arterial disease or atheromata in the descending aorta. As such, we have not noticed an increased risk of stroke when a thoracoscopic approach is employed $(7,44)$. Furthermore, routine utilization of a Chitwood clamp for aortic crossclamping minimizes the risk of iatrogenic aortic dissection from endoaortic balloon occlusion (45).

Although we believe thoracoscopy-assisted mitral valve surgery to be the most favorable approach, we do not believe it absolute in all situations. Although a number of series demonstrate excellent outcomes of thoracoscopic mitral valve surgery in higher risk groups, including the elderly (29), obese (30), reoperative cardiac surgery patients (46) or even those with significant left ventricular dysfunction (47), the choice of operative approach must be made on an individual basis. Operative approach should be tailored to patient preferences, the anatomy and disease etiology, the comfort level of the surgeon with the approach to be utilized, and other risk factors that may make one approach preferable to others.

\section{Acknowledgements}

None.

\section{Footnote}

Conflicts of Interest: The authors have no conflicts of interest to declare.

\section{References}

1. Goldstone AB, Joseph Woo Y. Minimally invasive surgical treatment of valvular heart disease. Semin Thorac Cardiovasc Surg 2014;26:36-43.

2. Woo YJ. Minimally invasive valve surgery. Surg Clin North Am 2009;89:923-49, x.

3. Woo YJ, Goldstone AB. The contemporary evolution of mitral valve surgery. J Thorac Cardiovasc Surg 2016;151:7-9.

4. Grossi EA, LaPietra A, Ribakove GH, et al. Minimally invasive versus sternotomy approaches for mitral reconstruction: comparison of intermediate-term results. J Thorac Cardiovasc Surg 2001;121:708-13.

5. Svensson LG, Atik FA, Cosgrove DM, et al. Minimally invasive versus conventional mitral valve surgery: a propensity-matched comparison. J Thorac Cardiovasc Surg 2010;139:926-32.e1-2.

6. Iribarne A, Russo MJ, Easterwood R, et al. Minimally invasive versus sternotomy approach for mitral valve surgery: a propensity analysis. Ann Thorac Surg 2010;90:1471-7; discussion 1477-8.

7. Goldstone $\mathrm{AB}$, Atluri $\mathrm{P}$, Szeto WY, et al. Minimally invasive approach provides at least equivalent results for surgical correction of mitral regurgitation: a propensitymatched comparison. J Thorac Cardiovasc Surg 2013;145:748-56.

8. Dogan S, Aybek T, Risteski PS, et al. Minimally invasive port access versus conventional mitral valve surgery: prospective randomized study. Ann Thorac Surg 2005;79:492-8.

9. Modi P, Hassan A, Chitwood WR Jr. Minimally invasive mitral valve surgery: a systematic review and meta-analysis. Eur J Cardiothorac Surg 2008;34:943-52.

10. Cheng DC, Martin J, Lal A, et al. Minimally invasive versus conventional open mitral valve surgery: a metaanalysis and systematic review. Innovations (Phila) 2011;6:84-103.

11. Mohr FW, Falk V, Diegeler A, et al. Minimally invasive port-access mitral valve surgery. J Thorac Cardiovasc Surg 1998;115:567-74; discussion 574-6.

12. Suri RM, Schaff HV, Meyer SR, et al. Thoracoscopic versus open mitral valve repair: a propensity score analysis of early outcomes. Ann Thorac Surg 2009;88:1185-90.

13. Sündermann SH, Sromicki J, Rodriguez Cetina Biefer H, et al. Mitral valve surgery: right lateral minithoracotomy or sternotomy? A systematic review and meta-analysis. J Thorac Cardiovasc Surg 2014;148:1989-1995.e4.

14. Reser D, van Hemelrijck M, Pavicevic J, et al. Repair rate and durability of video assisted minimally invasive mitral valve surgery. J Card Surg 2014;29:766-71.

15. Goldstone AB, Cohen JE, Howard JL, et al. A "RepairAll" Strategy for Degenerative Mitral Valve Disease Safely Minimizes Unnecessary Replacement. Ann Thorac Surg 2015;99:1983-90; discussion 1990-1.

16. Borger MA, Kaeding AF, Seeburger J, et al. Minimally invasive mitral valve repair in Barlow's disease: early and long-term results. J Thorac Cardiovasc Surg 2014;148:1379-85. 
17. Grossi EA, Galloway AC, Ribakove GH, et al. Minimally invasive port access surgery reduces operative morbidity for valve replacement in the elderly. Heart Surg Forum 1999;2:212-5.

18. Cohn LH, Adams DH, Couper GS, et al. Minimally invasive cardiac valve surgery improves patient satisfaction while reducing costs of cardiac valve replacement and repair. Ann Surg 1997;226:421-6; discussion 427-8.

19. Chitwood WR Jr, Wixon CL, Elbeery JR, et al. Videoassisted minimally invasive mitral valve surgery. J Thorac Cardiovasc Surg 1997;114:773-80; discussion 780-2.

20. Bolotin G, Kypson AP, Reade CC, et al. Should a videoassisted mini-thoracotomy be the approach of choice for reoperative mitral valve surgery? J Heart Valve Dis 2004;13:155-8; discussion 158.

21. Felger JE, Chitwood WR Jr, Nifong LW, et al. Evolution of mitral valve surgery: toward a totally endoscopic approach. Ann Thorac Surg 2001;72:1203-8; discussion 1208-9.

22. Woo YJ, Nacke EA. Robotic minimally invasive mitral valve reconstruction yields less blood product transfusion and shorter length of stay. Surgery 2006;140:263-7.

23. Grossi EA, Galloway AC, Ribakove GH, et al. Impact of minimally invasive valvular heart surgery: a case-control study. Ann Thorac Surg 2001;71:807-10.

24. Horvath KA, Acker MA, Chang H, et al. Blood transfusion and infection after cardiac surgery. Ann Thorac Surg 2013;95:2194-201.

25. Richardson L, Richardson M, Hunter S. Is a port-access mitral valve repair superior to the sternotomy approach in accelerating postoperative recovery? Interact Cardiovasc Thorac Surg 2008;7:678-83.

26. Glower DD, Landolfo KP, Clements F, et al. Mitral valve operation via Port Access versus median sternotomy. Eur J Cardiothorac Surg 1998;14 Suppl 1:S143-7.

27. Walther T, Falk V, Metz S, et al. Pain and quality of life after minimally invasive versus conventional cardiac surgery. Ann Thorac Surg 1999;67:1643-7.

28. Mihaljevic T, Cohn LH, Unic D, et al. One thousand minimally invasive valve operations: early and late results. Ann Surg 2004;240:529-34; discussion 534.

29. Iribarne A, Easterwood R, Russo MJ, et al. Comparative effectiveness of minimally invasive versus traditional sternotomy mitral valve surgery in elderly patients. J Thorac Cardiovasc Surg 2012;143:S86-90.

30. Santana O, Reyna J, Grana R, et al. Outcomes of minimally invasive valve surgery versus standard sternotomy in obese patients undergoing isolated valve surgery. Ann Thorac Surg 2011;91:406-10.

31. Casselman FP, Van Slycke S, Dom H, et al. Endoscopic mitral valve repair: feasible, reproducible, and durable. J Thorac Cardiovasc Surg 2003;125:273-82.

32. Vleissis AA, Bolling SF. Mini-reoperative mitral valve surgery. J Card Surg 1998;13:468-70.

33. Navia JL, Cosgrove DM 3rd. Minimally invasive mitral valve operations. Ann Thorac Surg 1996;62:1542-4.

34. Iribarne A, Easterwood R, Russo MJ, et al. A minimally invasive approach is more cost-effective than a traditional sternotomy approach for mitral valve surgery. J Thorac Cardiovasc Surg 2011;142:1507-14.

35. Grossi EA, Goldman S, Wolfe JA, et al. Minithoracotomy for mitral valve repair improves inpatient and postdischarge economic savings. J Thorac Cardiovasc Surg 2014;148:2818-22.e1-3.

36. Mihaljevic T, Jarrett CM, Gillinov AM, et al. Robotic repair of posterior mitral valve prolapse versus conventional approaches: potential realized. J Thorac Cardiovasc Surg 2011;141:72-80.e1-4.

37. Nifong LW, Rodriguez E, Chitwood WR Jr, et al. 540 consecutive robotic mitral valve repairs including concomitant atrial fibrillation cryoablation. Ann Thorac Surg 2012;94:38-42; discussion 43.

38. Suri RM, Burkhart HM, Daly RC, et al. Robotic mitral valve repair for all prolapse subsets using techniques identical to open valvuloplasty: establishing the benchmark against which percutaneous interventions should be judged. J Thorac Cardiovasc Surg 2011;142:970-9.

39. Ramzy D, Trento A, Cheng W, et al. Three hundred robotic-assisted mitral valve repairs: the Cedars-Sinai experience. J Thorac Cardiovasc Surg 2014;147:228-35.

40. Suri RM, Taggarse A, Burkhart HM, et al. Robotic Mitral Valve Repair for Simple and Complex Degenerative Disease: Midterm Clinical and Echocardiographic Quality Outcomes. Circulation 2015;132:1961-8.

41. Cao C, Wolfenden H, Liou K, et al. A meta-analysis of robotic vs. conventional mitral valve surgery. Ann Cardiothorac Surg 2015;4:305-14.

42. Holzhey DM, Seeburger J, Misfeld M, et al. Learning minimally invasive mitral valve surgery: a cumulative sum sequential probability analysis of 3895 operations from a single high-volume center. Circulation 2013;128:483-91.

43. Chitwood WR Jr, Rodriguez E, Chu MW, et al. Robotic 
mitral valve repairs in 300 patients: a single-center experience. J Thorac Cardiovasc Surg 2008;136:436-41.

44. MacArthur JW Jr, Cohen JE, Goldstone AB, et al. Nonresectional single-suture leaflet remodeling for degenerative mitral regurgitation facilitates minimally invasive mitral valve repair. Ann Thorac Surg 2013;96:1603-6.

45. Atluri P, Goldstone AB, Fox J, et al. Port access cardiac operations can be safely performed with either endoaortic balloon or Chitwood clamp. Ann Thorac Surg

Cite this article as: Goldstone $\mathrm{AB}$, Woo $\mathrm{YJ}$. Is minimally invasive thoracoscopic surgery the new benchmark for treating mitral valve disease? Ann Cardiothorac Surg 2016;5(6):567-572. doi: 10.21037/acs.2016.03.18
2014;98:1579-83; discussion 1583-4.

46. Vallabhajosyula P, Wallen T, Pulsipher A, et al. Minimally Invasive Port Access Approach for Reoperations on the Mitral Valve. Ann Thorac Surg 2015;100:68-73.

47. Atluri P, Woo YJ, Goldstone AB, et al. Minimally invasive mitral valve surgery can be performed with optimal outcomes in the presence of left ventricular dysfunction. Ann Thorac Surg 2013;96:1596-601; discussion 1601-2. 